\title{
OTIMIZAÇÃO DO PROCESSO DE ANÁLISE DOS DADOS COLETADOS \\ SOBRE A APLICAÇÃO DA METODOLOGIA DE APRENDIZAGEM BASEADA EM PROBLEMAS E PROJETOS NO CURSO DE ENGENHARIA DE COMPUTAÇÃO DA UEFS
}

\author{
Fábio Barros de Almeida ${ }^{1}$; Elisângela Oliveira Carneiro ${ }^{2}$ \\ 1. Bolsista PROBIC/UEFS, Graduando em Engenharia de Computação, Universidade Estadual de Feira de Santana, \\ e-mail: fabugo@gmail.com.br \\ 2. Orientador, Departamento de Tecnologia, Universidade Estadual de Feira de Santana, \\ e-mail: elisangela@ecomp.uefs.br
}

PALAVRAS-CHAVE: Aprendizagem Baseada em Problemas; Aprendizagem baseada em projetos; Avaliação de aprendizagem.

\section{INTRODUÇÃO}

O curso de Engenharia de Computação da UEFS foi implantado no ano de 2003, e desde o início, em parte das disciplinas obrigatórias se aplicam o uso da metodologia PBL [5][8] (do inglês Problem Based Learning)[2]. Com a constante necessidade de acompanhar os resultados dessa aplicação[5][7][9], em 2009 foi formalizada uma Comissão, que é subdividida em i) elaboração dos problemas; ii) papéis desempenhados pelo tutor; iii) planejamento e acompanhamento dos estudos integrados.

As subcomissões aplicam questionários com discentes e fazem reuniões com docentes, a fim de levantar informações sobre as práticas pedagógicas, também apresentam resultados das informações levantadas e realizam oficinas para novos professores. Com essa avaliação docente, é possível corrigir os objetivos e trabalhar as boas práticas, e com isso é esperado melhorias no processo ensino aprendizagem[6].

A coleta de dados, realizada através da aplicação de questionários quantitativos impresso, em salas de aulas, são inseridos em um banco de dados por meio de scripts computacionais. Apesar desse mecanismo ser eficaz, a etapa de processamento de dados, no qual consiste em gerar gráficos e tabelas para análises e conclusões, precisa ser otimizada. Assim esse trabalho consistiu em otimizar essa etapa, através da criação de um sistema web, utilizando as informações armazenadas no banco de dados já desenvolvido. Além de fazer novas coletas para manter os dados atualizados.

\section{MATERIAL E MÉTODOS OU METODOLOGIA}

O trabalho foi iniciado com revisões bibliográficas e pesquisas na área de desenvolvimento de software, desenvolvimento de sistemas web e criação de gráficos. O objetivo foi conhecer melhor a arquitetura web, definir ferramentas de desenvolvimentos, considerando como requisito fundamental a geração de gráficos.

Feito isso foi realizado o levantamento de requisitos do sistema, para assim documentar o funcionamento do sistema a ser desenvolvido, quais são suas funcionalidade e como deve se comportar. Com base nesses requisitos, foi construído protótipos do sistema, imagens das páginas web que o sistema apresentaria, Figura 1. 

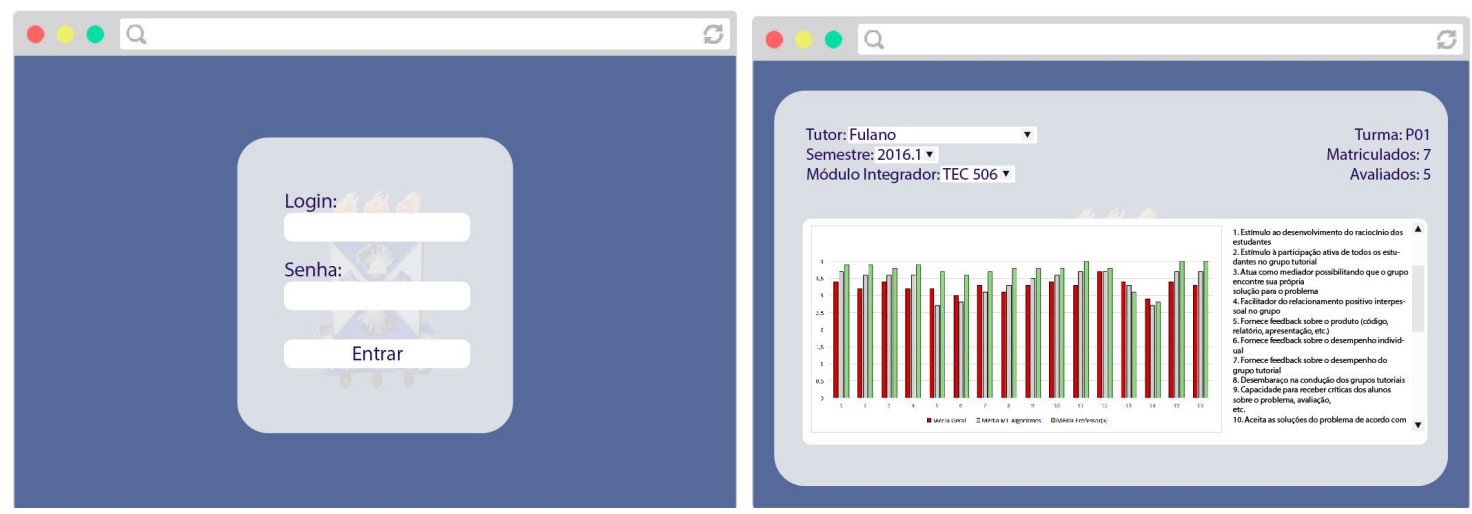

Figura 1. Protótipo da interface

Com as telas definidas partimos para o desenvolvimento do sistema, que é dividido em servidor web, servidor de aplicação e servidor de dados. Em paralelo a isso, foi feita a coleta de dados quantitativos através da aplicação de questionários, para atualizar os dados do banco de dados e para apresentar novos relatórios e apresentações.

\section{RESULTADOS E/OU DISCUSSÃO}

Depois de pesquisar sobre todos aspectos necessários para desenvolvimento de um sistema WEB, o próximo passo foi decidir qual tecnologia ia ser usada para desenvolver o servidor de aplicação. Para isso, foi considerado vantagens e desvantagens [4] de cada uma delas e também com qual delas o bolsista teria mais agilidade, já que todas atendem aos aspectos do projeto. Deste modo, acabamos por escolher o PHP e PHPlot. Após as escolhas das ferramentas, foram definidos os seguintes requisitos do sistema:1) Autenticação de professor/tutor: entrar no sistema após autenticação com os dados do usuário e senha; 2) Gerar gráfico relacionados ao professor/tutor autenticado, para visualização das informações coletadas informando o semestre e o MI (Módulo Integrador); 3) Apresentação do gráfico: o gráfico contém informações resumidas sobre o professor/tutor, quantidade de alunos matriculados no MI e quantidade de alunos que participaram da avaliação. O gráfico apresenta as médias das notas atribuídas ao tutor em cada pergunta, bem como a média geral de todos os tutores por pergunta. 4) Informações adicionais: apresentação das listas de questões avaliadas.

Definido a tecnologia, os requisitos e protótipos das telas do sistema, Figura 1, se iniciou o desenvolvimento do servidor de aplicação. No servidor WEB foi utilizado bootstrap para construir páginas com agilidade e responsividade (adaptável a visualização em diferentes tipos de dispositivos)

A Figura 2 apresenta a interface de autenticação para que o tutor/professor possa acessar o sistema. Os campos email e senha devem ser cadastrados previamente, não foi desenvolvido nenhuma interface de cadastro de tutores/professores, assim nessa etapa os cadastros são realizados manualmente direto no banco de dados. Assim que o tutor/professor preenche os dados, o servidor de aplicação busca os dados cadastrados e valida sua senha, permitindo a entrada do mesmo no sistema. 


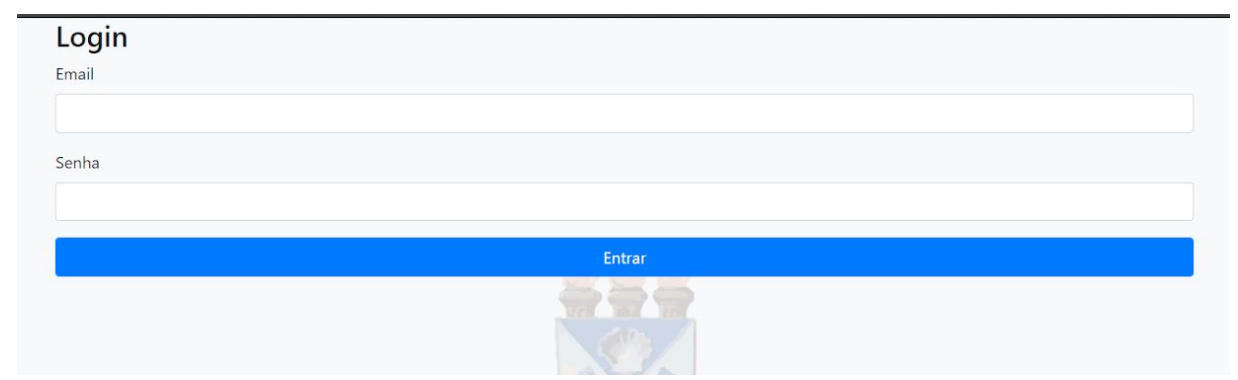

Figura 2. Interface desenvolvida da Autenticação do Professor.

$\mathrm{Na}$ figura 3 temos os campos para gerar o gráfico, informando o semestre e MI e clicando no botão gerar, as informações dos campos são enviadas para o servidor de aplicação, que ao receber as informações faz uma busca ao banco de dados onde está armazenado os dados coletados. Depois que a busca dos dados for realizada, ainda o servidor de aplicação constrói o grafico por meio da biblioteca PHPlot, que por final envia ao servidor WEB que constrói a página WEB que é possível visualizar nos navegadores. Assim o navegador exibe o gráfico gerado pelo sistema como mostra a figura 4 e abaixo do gráfico aparece uma lista em tabela com as descrições de cada questão.

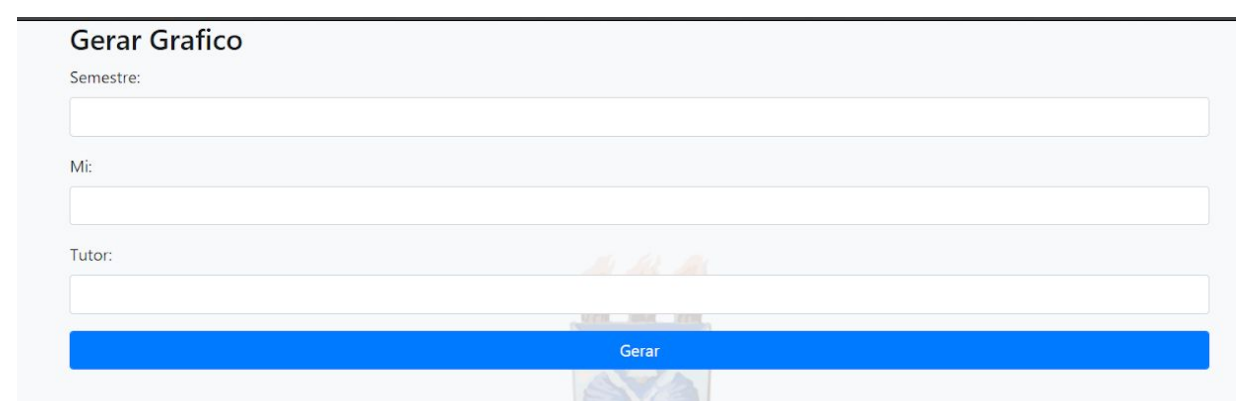

Figura 3. Formulário de Entrada para Gerar Gráfico.

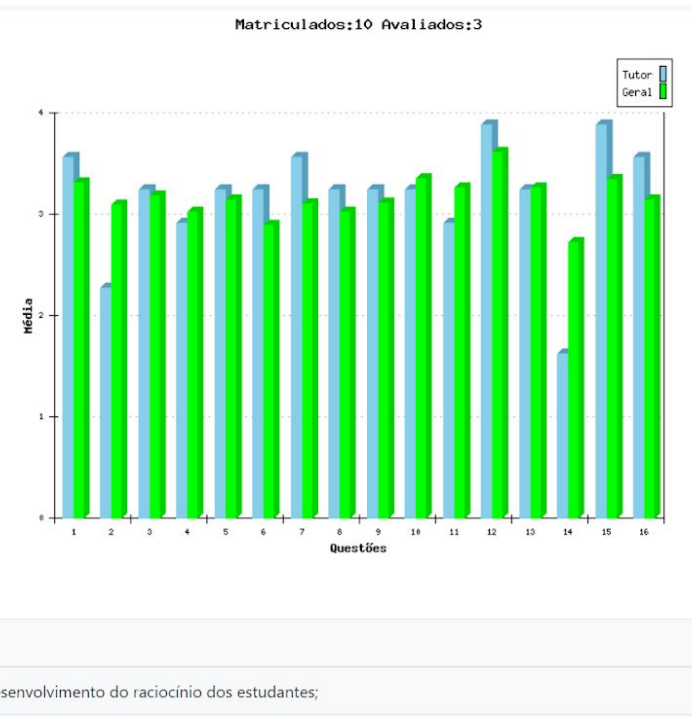

Figura 4. Gráfico Gerado com PHPlot.

Em paralelo a construção do webapp foi realizado nova coleta de dados, atualizando o banco de dados com novas análises. Nessa coleta contamos com a participação de 170 alunos, foram avaliadas 25 turmas alcançando $65 \%$ do total de alunos matriculados nos Módulos Integradores. 
Além disso foi notado notas abaixo de três (regular/pouco) para duas questões. Nota 2.7 para questão 14 (Agilidade na correção dos produtos, divulgando as notas 48 horas antes da entrega do próximo produto, pelo menos) e nota 2.9 para questão 6 (Fornece feedback sobre o desempenho individual).

\section{CONSIDERAÇÕES FINAIS}

O trabalho planejado de otimização do processo foi realizado, sendo possível visualizar gráficos e dados sobre a aplicação do PBL no sistema web.

O sistema não foi hospedado e consequentemente não foi testado como necessário, assim é fundamental que em atividades futuras, o sistema seja testado com o usuário final (tutor/professor) em um ambiente definitivo.

Além disso o sistema desenvolvido pode receber novas atualizações, unificar o mecanismo de inserção dos dados coletados ao banco de dados e de geração de gráficos, seria melhorias futuras interessantes. Assim futuramente não seja necessário conhecimentos técnicos sobre scripts ou de programação para operar o sistema como todo, sendo assim possível aplicar o sistema em outros tipos de avaliações quantitativas.

\section{REFERÊNCIAS}

[1] ANGELO, M. F.; BERTONI, F. Análise da Aplicação do Método PBL no Processo de Ensino e Aprendizagem em um Curso de Engenharia de Computação. Acesso em: 30 mar. 2016.

[2] BARROWS, H. S. A taxonomy of problem-based learning methods. Medical education, vol.20, n. 6, pp. 481-486, 1986.

[5] BITTENCOURT, R.; FIGUEIREDO, O. A.O Currículo do Curso de Engenharia de Computação da UEFS: Flexibilização e Integração Curricular. In: Anais do XXIII Congresso da Sociedade Brasileira de Computação - XI WEI - XI Workshop sobre Educação em Computação. 2003.

[4]GIROTO, Fernando. Escolhendo a linguagem: asp.net,Ruby on Rails, Django, Phyton ou Php? Disponível em: $<$ https://pt.linkedin.com/pulse/apare\%C3\%A7a-na-m\%C3\%ADdia-luis-giroto $>$. Acesso em: 15 ago. 2018.

[6] MATOS, D. A. S.; CIRINO D. S.; BROWN G. T. L.; LEITE W. L. Avaliação no ensino superior: concepções múltiplas de estudantes brasileiros. 2013.

[7] SANTANA, F. C. B; SOUZA, J. M. S; SANTOS, J. A. M.; NASCIMENTO, N. M. Análise de Problemas Aplicados em um Estudo Integrado de Linguagens de Programação utilizando PBL. 2010.

[8] SANTOS, D; PINTO, C. S.; BERTONI, F.; BITTENCOURT, R. Aplicação do Método de Aprendizagem Baseada em Problemas no Curso de Engenharia de Computação da Universidade Estadual de Feira de Santana. In: Anais do XXXV Congresso Brasileiro de Educação em Engenharia. 2007.

[9] SANTOS, J. A. M.; ANGELO, M. F. "Experiências em um Estudo Integrado de Programação usando PBL,". In: Anais: XXVIII Congresso da Sociedade Brasileira de Computação - XVI WEI - XVI Workshop sobre Educação em Computação, 2008. 